\title{
Suitability of power-law extrapolation for wind speed estimation on a tropical island
}

\author{
Jing-Jin TIEO ${ }^{\mathrm{a}, \mathrm{b}, *}$, Martin SKOTE ${ }^{\mathrm{c}}$, Narasimalu SRIKANTH ${ }^{\mathrm{b}, *}$ \\ anterdisciplinary Graduate School, Nanyang Technological University, Singapore 639798, Singapore. \\ bEnergy Research Institute @ NTU, Nanyang Technological University, Singapore 637141, Singapore. \\ 'School of Aerospace, Transport and Manufacturing, Cranfield University, Cranfield MK43 0AL, United \\ Kingdom.
}

\begin{abstract}
In this study, the ability of the power-law wind model to reproduce a tropical vertical wind profile is investigated. Data from a one-year observation on an offshore island of Singapore, obtained using a lidar, are used to show that the power-law model profiles are unable to capture the pertinent features of the observed wind profiles. Two alternative profile models, one based on the free convection limit scaling and the other based on the arctangent function, are introduced and tested. The latter model, although lacking physical basis, is found to be superior in predicting the measured profiles. A systematic study of the seasonal and diurnal variations of the model parameters is presented and some practical implications of the results are also discussed.
\end{abstract}

Keywords: wind profile, boundary layer, power law, tropics, lidar.

\section{Introduction}

While the use of wind energy as a renewable energy source has seen substantial growth in many parts of the world [1,2], its potential remains relatively untapped in the deep tropics. There are two main reasons for this. First, wind speeds in the tropics, particularly near the equator between the $15^{\circ} \mathrm{N}$ and $15^{\circ} \mathrm{S}$ latitudes, are generally low and do not present a strong case for the deployment of contemporary large wind turbines. Second, the abundance of solar radiation in the tropics also means that solar energy is the more readily-accessible and thus preferred form of renewable energy in the region. Despite this, recent advances in the development of low-speed wind turbines are making the prospect of wind energy more appealing in the tropics. Developments in the area of small wind turbines for urban and microgrid applications are also opening up new opportunities where wind energy systems can be deployed [3,4]. As such, the growth of wind energy in the region can be expected to accelerate in the near future.

Aside from wind energy, the knowledge of the wind characteristics is important in other areas such as for the calculation of wind loads on buildings and for the planning of airport infrastructure and terminal flight procedures. The depiction of local winds is also essential as a boundary condition for the numerical mapping of wind resources and pollution dispersion $[5,6]$. Most current methods and models used in the prediction of wind characteristics were developed based on experiments conducted in extra-tropical locations [7-10]. Unlike at the higher latitudes, atmospheric circulation in the tropics is primarily driven by direct solar heating. Geostrophic winds, which dominate much of extra-tropical weather, are almost non-existent due to the weak Coriolis force near the equator [11]. Many parts of the tropics also experience seasonal monsoon winds which change direction twice a year. In light of the different mechanisms that drive tropical weather, it is important to re-examine the validity of some of the methods and assumptions that current wind assessment studies rely on. 
One particular wind characteristic of interest to wind engineers and atmospheric scientists is the vertical wind shear profile: the variation of wind speed with height. The conventional wisdom is that the higher you go, the stronger the winds. This characteristic is embodied in the widely-known and mathematically simple power-law profile [12], which predicts monotonically increasing wind speed with height. However, the power-law profile model does not explicitly account for the effects of atmospheric stability and surface roughness [13]. A more rigorous model which does account for these effects is the log-law profile with stability corrections first proposed by Monin and Obukhov in 1954 [14] and sometimes referred to as the Monin-Obukhov similarity theory (MOST). While the log-law model does explicitly account for atmospheric stability and surface roughness by accepting the relevant parameterisations as variables in the profile equation, the correct forms of the stability correction functions remain an open question for discussion and active research [7,15-17]. As of yet, no correction functions are universally applicable for all atmospheric conditions. Despite the inherent shortcomings of the power-law and log-law profile models, they are widely used for practical wind assessment applications [18-21] and the power-law profile is particularly convenient as a first-pass approximation for estimating wind speeds at various heights. We aim, in the present work, to construct an alternative for the power-law model which is valid in tropical regions while retaining its simplicity, thus distinguishing it from the more common MOST-based approach.

This paper presents a data-driven study of the vertical wind shear profiles over an offshore island of Singapore. Located on the southern tip of the Malay Peninsula in Southeast Asia and at $1^{\circ}$ north of the equator, Singapore experiences tropical weather patterns and is affected by the Asian monsoon. The aim is to investigate how well the power-law profile model represents the main features of the measured wind shear profiles and propose alternative empirical models that can better capture the shape of the observed profiles. Of the two alternative models introduced, one is based on the free convection limit scaling whereas the other, employing the arctangent function, is purely empirical and does not have a physical basis. The paper is structured as follows: The next section provides a description of the existing and proposed wind shear profile models. Section 3 gives a description of the observation site and its meteorology, as well as the steps taken to process and analyse the data. Section 4 presents the results and discussion. Finally, Section 5 concludes the paper.

\section{Wind shear profile models}

\section{$\underline{2.1 \text { Existing wind shear profile models }}$}

\subsubsection{Power-law profile}

The power-law profile model [12] is a well-known vertical wind shear profile that allows the wind speeds at different heights to be easily extrapolated from a single measurement at some reference height, usually at $10 \mathrm{~m}$. The profile is given by:

$$
u=u_{\mathrm{ref}}\left(\frac{z}{z_{\mathrm{ref}}}\right)^{\alpha}
$$


where $u$ and $z$ denote the wind speed and vertical height, respectively, and $\alpha$ is the shear coefficient. The term $u_{\text {ref }}$ denotes the measured reference wind speed at the reference height $z_{\text {ref. }}$ The profile has the advantage of being simple to manipulate mathematically and it contains only a single parameter, $\alpha$, which controls the shape of the profile curve. A commonly-cited value for $\alpha$ is $1 / 7(\approx 0.14)$ but various experiments in literature have uncovered differing values of $\alpha$ for different atmospheric and surface conditions [2225]. The main drawback of the power-law profile is its inability to explicitly account for these varying conditions, namely in the form of the atmospheric stability and surface roughness. Even though there have been research conducted into casting $\alpha$ as an explicit function of atmospheric stability and surface roughness [26,27], such methods are not widely adopted.

\subsubsection{Log-law profile}

An alternative to the power-law profile that does account for the surface roughness is the log-law profile model. It is commonly stated together with a stability correction term which corrects the base log-law profile for different atmospheric stabilities. The profile equation is given by:

$$
u=\frac{u^{*}}{\kappa}\left(\ln \left(\frac{Z}{z_{0}}\right)+\Psi\left(\frac{Z}{L}\right)\right)
$$

where $z_{0}$ is the roughness length, which parameterises the surface roughness, and $\Psi$ is the stability correction function which takes the argument $z / L$ where $L$ is the MoninObukhov length, a parameterisation of atmospheric stability. $u^{*}$ and $\kappa$ are the friction velocity and von Kármán constant, respectively. Unlike the power-law profile, the loglaw profile accounts explicitly for the surface roughness and atmospheric stability through the parameters $z_{0}$ and $L$. However, this comes at a price of much increased complexity in working with the profile equation. To fully define the profile, four parameters or constants have to be determined or assumed and an appropriate form of the stability correction function, which itself contains additional empirical constant(s), have to be selected. The effects of the parameters on the profile shape are also less obvious compared to the effects of $\alpha$ on the power-law profile shape. To that end, Holtslag et al. investigated the effects of $z_{0}$ and $L$ on the log-law profile shape and reported the results in their recent paper [28]. They found that varying $z_{0}$ results in a change in the predicted wind speeds, essentially a translation of the profile curve along the speed-axis, but does not change the profile shape. Varying $L$ changes the wind shear with the wind speed increasing more quickly with height under a stable condition as compared to neutral, whereas the wind speed increases more slowly under an unstable condition.

\section{$\underline{2.1 .3 \text { Other profile models }}$}

In the effort to achieve better predictions of the observed vertical wind profiles obtained in experimental studies, several authors have proposed modifications to the basic wind profile models described above. One example is Gryning et al. [8] who attempted to construct a wind profile that can produce more accurate predictions of wind speeds throughout the entire atmospheric boundary layer, up to a height of $1000 \mathrm{~m}$. The authors were particularly interested in correcting the profile for heights above the surface layer where the performance of the log-law profile is known to be poor. By modifying the 
length scale used in the derivation of the original log-law profile, they were able to derive new profile equations for atmospheres with neutral, stable, and unstable stratification. A similar attempt to obtain an extended boundary-layer profile, valid only for the neutral stratification, was also attempted earlier by Deaves and Harris [29]. In their so-called Deaves \& Harris model, a correction function in the form of a parabolic function is added to the log-law wind profile. By introducing the boundary-layer height as an additional parameter, the resulting profile equation represents a more realistic bounded boundary layer as opposed to the infinite boundary layer modelled by the power-law or log-law profile models.

Another study that investigated boundary-layer wind profiles was reported by Grachev et al. [30] who re-examined some of the assumptions used in deriving the wind profile equations, specifically when applied to an unstably-stratified atmosphere. By using revised parameterisations more appropriate for a highly-convective boundary layer, they obtained expressions which suggest that the wind speed in a convective atmospheric boundary layer scales with the -1/3-power of vertical height. It was concluded that the new resultant profiles were a better match with the experimental observations. Interestingly, the 1/3-exponent also appears in some suggested forms of the log-law stability correction function for an unstable convective atmosphere [31].

\subsection{Proposed wind shear profile models}

The main impetus of this study is to assess the suitability of the power-law wind profile when applied in the tropics. Aside from the power-law model (Eq. 1), two alternative wind profile models are introduced here that can better fit the wind profiles obtained from the observation data. The two alternative profile models will be referred to as the -1/3-exponent model and the arctangent ('arctan') model.

\subsection{1 -1/3-exponent model}

The -1/3-exponent model was inspired by the expressions derived in Grachev et al. [30] which suggest that the wind speed $u$ scales with the $-1 / 3$-power of vertical height $z$ (i.e. $z^{-1 / 3}$ ) in the free convection limit. Specifically, the Equations (15) and (17) obtained in the paper, which represent convectively-unstable conditions, can both be easily rearranged to the form given by Equation (3) below. Hence, the profile equation for the -1/3-exponent model is:

$$
u=u_{\beta}-\beta z^{-\frac{1}{3}}, \beta>0
$$

with the parameters $u_{\beta}$ and $\beta$. Unlike the power-law and log-law profiles, where the wind speed can increase without bounds as height increases, the wind speed in the -1/3exponent model profile tends towards a finite value as the height increases. In this case, the parameter $u_{\beta}$ determines this limiting wind speed and $\beta$ determines how quickly the profile converges towards the limit. Another feature of the -1/3-exponent model profile is that the zero wind speed occurs at some non-zero height above the surface. This makes it in some sense relatable to the log-law profile in that both contain a roughness layer. 


\subsubsection{Arctangent model}

The profile equation of the arctan model, which was inspired solely by the shape of the observed wind profiles, is:

$$
u=u_{\tau}\left(\frac{2}{\pi}\right) \tan ^{-1}(\tau z), \tau>0
$$

where $u_{\tau}$ and $\tau$ are the parameters. Similar to the $-1 / 3$-exponent model, the wind speed in the arctan model is bounded. However, unlike the -1/3-exponent model, zero wind speed occurs on the surface at $z=0$. The parameter $u_{\tau}$ determines the limiting wind speed of the profile whereas $\tau$ determines how quickly the profile converges towards that speed with increasing height.

\section{Data and methodology}

\section{$\underline{3.1 \text { Site description }}$}

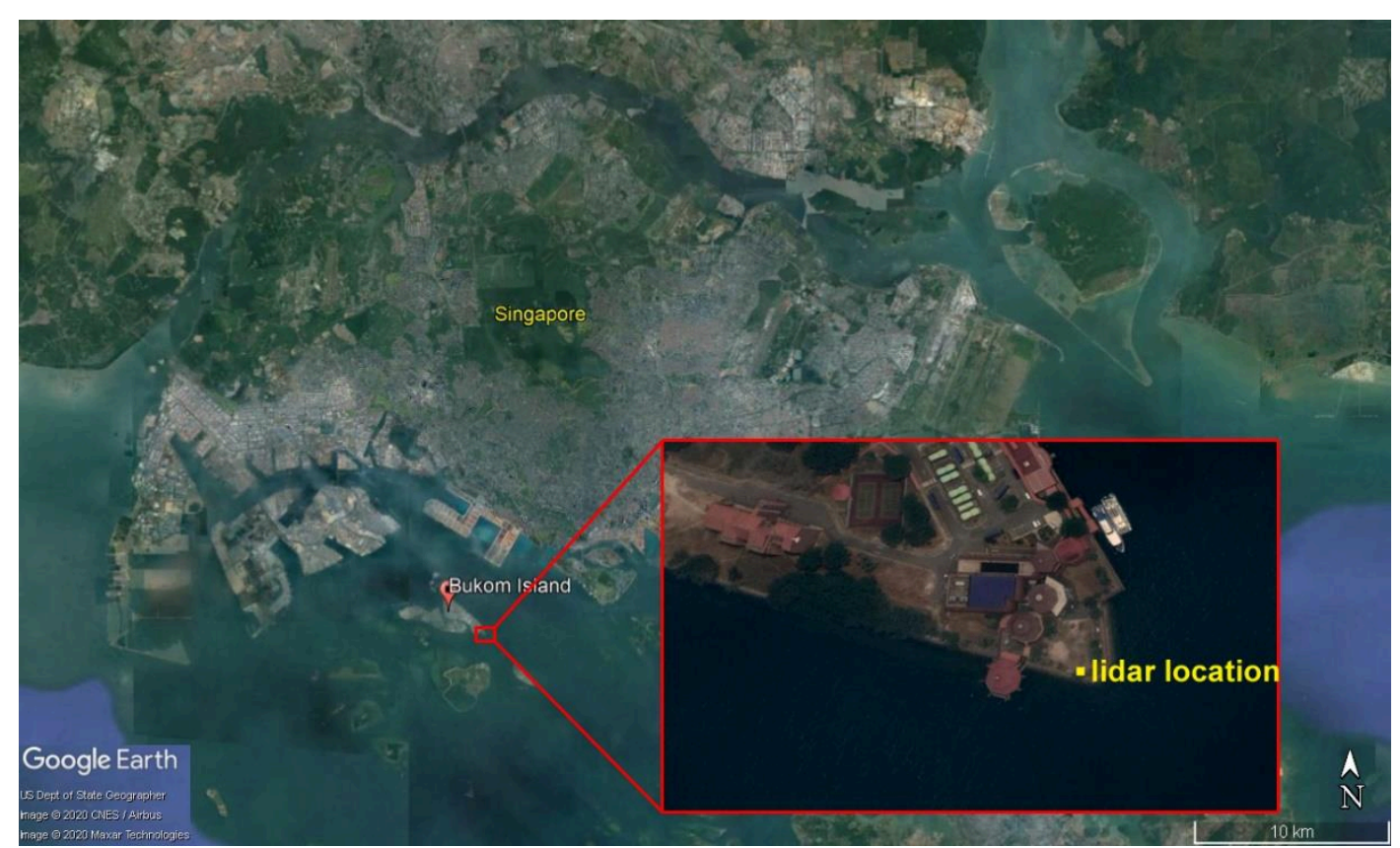

Figure 1: A satellite map showing the location of Pulau Bukom (Bukom Island) off the southwestern coast of Singapore with a zoomed insert showing the immediate vicinity of the lidar site. The location where the lidar was situated is marked by the yellow point. (Satellite imagery: CNES / Airbus, Maxar Technologies via Google Earth) 


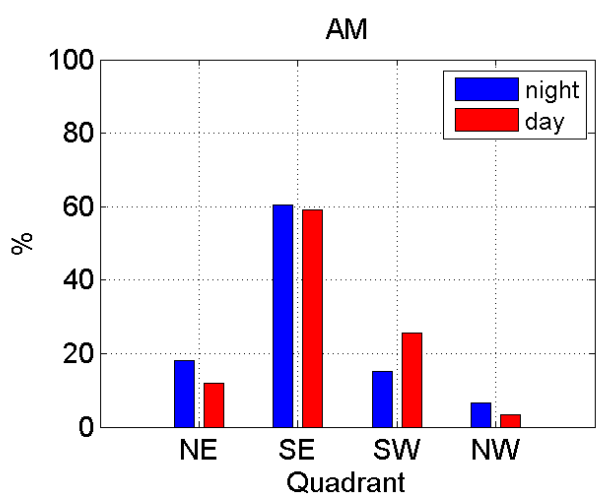

(a)

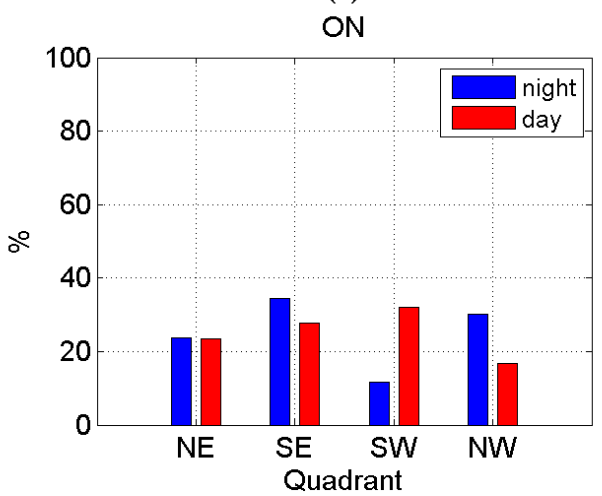

(c)

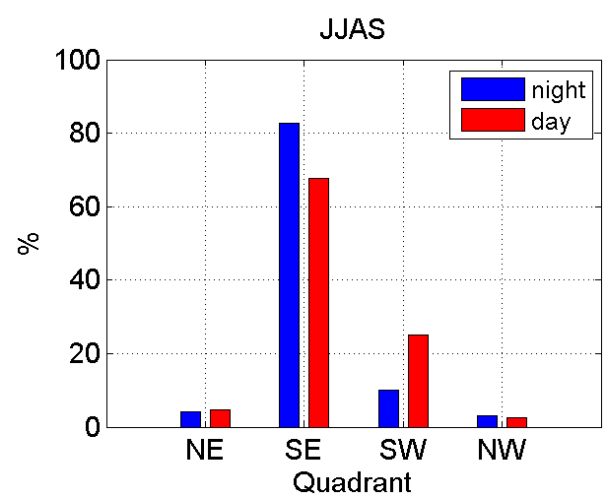

(b)

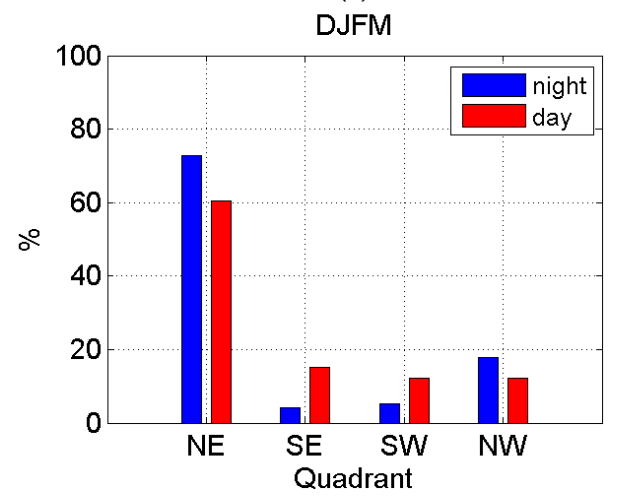

(d)

Figure 2: Percentage of 38-m wind data recorded in each of four direction quadrants for the seasons AM, JJAS, ON, and DJFM. The four direction quadrants are: northeast (NE $0^{\circ}-90^{\circ}$ ), southeast $\left(\mathrm{SE} 90^{\circ}-180^{\circ}\right.$ ), southwest (SW $\left.180^{\circ}-270^{\circ}\right)$, and northwest (NW $\left.270^{\circ}-360^{\circ}\right)$.

Wind data for this current study were collected on Pulau Bukom, an island off the southwest coast of Singapore, by means of a ZephIR 300 lidar unit. The island, whose location is shown on the map in Fig. 1, is about $4.5 \mathrm{~km}$ across and primarily houses an oil refinery and storage facility. Its terrain is entirely flat, and the surface comprises of man-made structures such as oil tanks and refinery buildings. The lidar was physically situated on the southeastern tip of the island at the coast, away from the main refinery plant.

Located at $1^{\circ} \mathrm{N}$ latitude, Singapore experiences typical tropical weather patterns characterised by strong sunshine, high rainfall, and relatively constant temperature throughout the year. The country also experiences the Asian monsoon which dominates the local wind pattern. There are two main monsoon seasons. During the southwest monsoon (JJAS), which lasts from June to September, winds predominantly come from the south. During the northeast monsoon (DJFM), which lasts from December to March, the winds switch to the opposite direction and predominantly come from the northeast. Winds during the northeast monsoon are also typically stronger than during the southwest monsoon. During the intervening inter-monsoon seasons which last from April to May (AM) and from October to November (ON), the winds are weaker than during the monsoon seasons and their direction is variable. A check with the collected wind direction data confirms that the monsoon characteristics of the wind were captured. This is shown in Fig. 2 where the percentages of wind data recorded in each of four direction quadrants (northeast, southeast, southwest, and northwest) are shown 
for each of the monsoon and inter-monsoon seasons. The definitions for 'night' and 'day' in the figure are explained in Section 3.3. With regards to the temperature, Singapore experiences its warmest months during the southwest monsoon when the daytime temperature is typically above $30{ }^{\circ} \mathrm{C}$. The coolest months are the northeast monsoon months of December and January when monsoon surges from the Greater Asian continent can sometimes cause the temperature to fall below $25^{\circ} \mathrm{C}$.

Another phenomenon experienced at the observation location is the diurnal variation of the wind owing to the coastal geography. Fig. 3 shows a plot of the hourly wind speed at the height of $10 \mathrm{~m}$ averaged over the entire period of the collected data. It shows a clear diurnal variation of the wind speed.

\subsection{Experiment and Data Measurement}

Lidar (LIght Detection And Ranging) [32,33] is a remote sensing device that was first developed in 1970s using gas laser but has further matured using solid state sources and telecommunication-based components. They operate with lasers of wavelength in the order of microns and operates based on the interaction of laser with the natural aerosols in the atmosphere (such as particles of dust, droplets, etc.) which results in back scattering of small fraction to the receiver. The motion of the particles helps measure wind speed and direction through the Doppler shift effect. This frequency shift is quantified by interacting the return signal with the original beam and identifying the beats at different frequency on a photodetector. Lasers offers the new remote sensing opportunity compared to conventional tall wind masts that requires site permitting, working at height, increased uncertainty of data reliability in complex sites and inadequate wind mast heights.

In the present study, ZephIR 300 lidar commercial model was used to measure wind characteristics from $10 \mathrm{~m}$ up to $200 \mathrm{~m}$ at a sampling rate of $50 \mathrm{~Hz}$. A Campbell Scientific CR800 datalogger is connected to the ZephIR 300, which transmits data over modem. The overall device is a mobile unit that can be handled and deployed easily in remote places. In the present study, firstly the lidar was deployed on the shores of Pulau Bukom at the coordinates $1.2241^{\circ} \mathrm{N}, 103.7788^{\circ}$ E. Secondly, wherever possible, IEA recommended practices for deploying and operating the lidar profiler and data quality control have been followed [34]. The lidar profiler was calibrated by the manufacturer and the calibration accuracy was validated against the measurements from a met mast. The calibration uncertainty ranged less than $0.1 \%$ and overall variation in calibration of less than $\pm 0.5 \%$ is assured.

\subsection{Data processing}

Data were collected for an almost one-year period from 21 November 2014 to 5 November 2015. Aside from a short break that occurred from 15 to 17 March 2015 due to equipment maintenance, there were no breaks in the data time series. Wind speed data were recorded at 11 heights of between $10 \mathrm{~m}$ and $200 \mathrm{~m}$ to form a vertical wind profile and these were logged at a rate of approximately 3 times per minute by the lidar datalogger. The heights at which the wind speeds were measured are: 10, 20, 30, 38, $50,60,75,90,120,150$, and $200 \mathrm{~m}$. The recorded wind profiles were then scrutinised and those with missing entries at any of the measurement heights were discarded. The valid profiles were then sorted according to the season and the local time $(\mathrm{UTC}+8)$ at 
which they were recorded. For the seasonal analysis, the four monsoon and intermonsoon seasons described earlier (AM, JJAS, ON, DJFM) were used. For the diurnal analysis, the profiles were classified as either a daytime 'day' profile or a night-time 'night' profile. Using Fig. 3 as a reference, the night period is defined as between 2200 and $1000 \mathrm{hrs}$ and the day period between 1000 and $2200 \mathrm{hrs}$ in order to equally divide the amplitude of the wind speed cycle into two halves. The sorted profiles for each season and diurnal period were then averaged to obtain a single mean profile for the subsequent analyses.

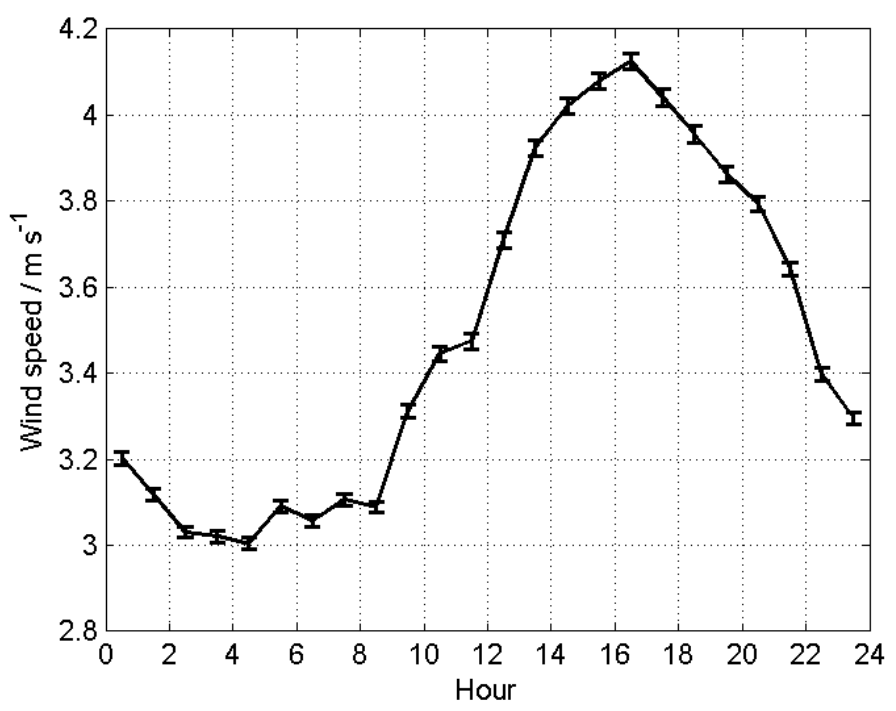

Figure 3: Averaged hourly wind speed (at 98\% confidence interval) at $10 \mathrm{~m}$ showing a clear diurnal cycle. Times shown are in local time $(\mathrm{UTC}+8)$.

\section{$\underline{\text { 3.4 Parameter determination and model error calculations }}$}

In order to assess the suitability of each of the profile models in their ability to reproduce the real averaged wind profile, a set of model parameters must first be determined by utilising the lidar observations. The errors between the model profile based on the parameters and the measured profile were then used as a gauge of the suitability of the model. A smaller error implies that the modelled profile matches more closely with the observed wind profile and thus can better predict the real-world condition. Qualitative observations of the modelled profiles versus the observed wind profiles were also made. For the power-law profile, curve fitting was performed by means of the ordinary leastsquares linear regression method applied on the logarithm of Equation (1), which yields a linear expression. Hence, the parameter $\alpha$ can be determined from the regression.

For the other two profile models, namely the -1/3-exponent model and the arctan model, curve fitting was achieved by non-linear iterative least-squares regression directly on the profile Equations (3) and (4) with the initial guesses for the parameters as $u_{\beta}, u_{\tau}=$ $1 \mathrm{~m} \mathrm{~s}^{-1}$ and $\beta, \tau=0.1$.

The errors for the respective model profiles were accounted for by the sums of the squared errors (SSEs). These were evaluated by first squaring at each observation height the difference of the wind speed between the measured wind profile and that predicted by the model. The differences were then summed up for all 11 of the observation heights. For the sake of clarity, the terms $\mathrm{SSE}_{\text {pow }}, \mathrm{SSE}_{1 / 3}$, and $\mathrm{SSE}_{\mathrm{tan}}$ are 
used to denote the SSEs for the power-law profile, the -1/3-exponent profile, and the arctan profile, respectively.

\section{Results and discussion}

The three profile models are discussed in the below sections with reference to Fig. 4, which shows the measured vertical wind profiles and the model profiles for the four seasons (AM, JJAS, ON, and DJFM) and the two diurnal time periods, night and day. The observed profile and the corresponding model profile were plotted on top of each other to allow qualitative comparisons of their shapes.

We can infer from Fig. 4 the seasonal and diurnal variations of the observed wind speed. The highest wind speeds were recorded in the DJFM season, followed by JJAS, and then followed by the inter-monsoon seasons. This is consistent with the known seasonal variation of the wind speed described earlier in Section 3.1. Diurnally, it can be observed that the wind speeds were higher during the day as compared to during the night. 

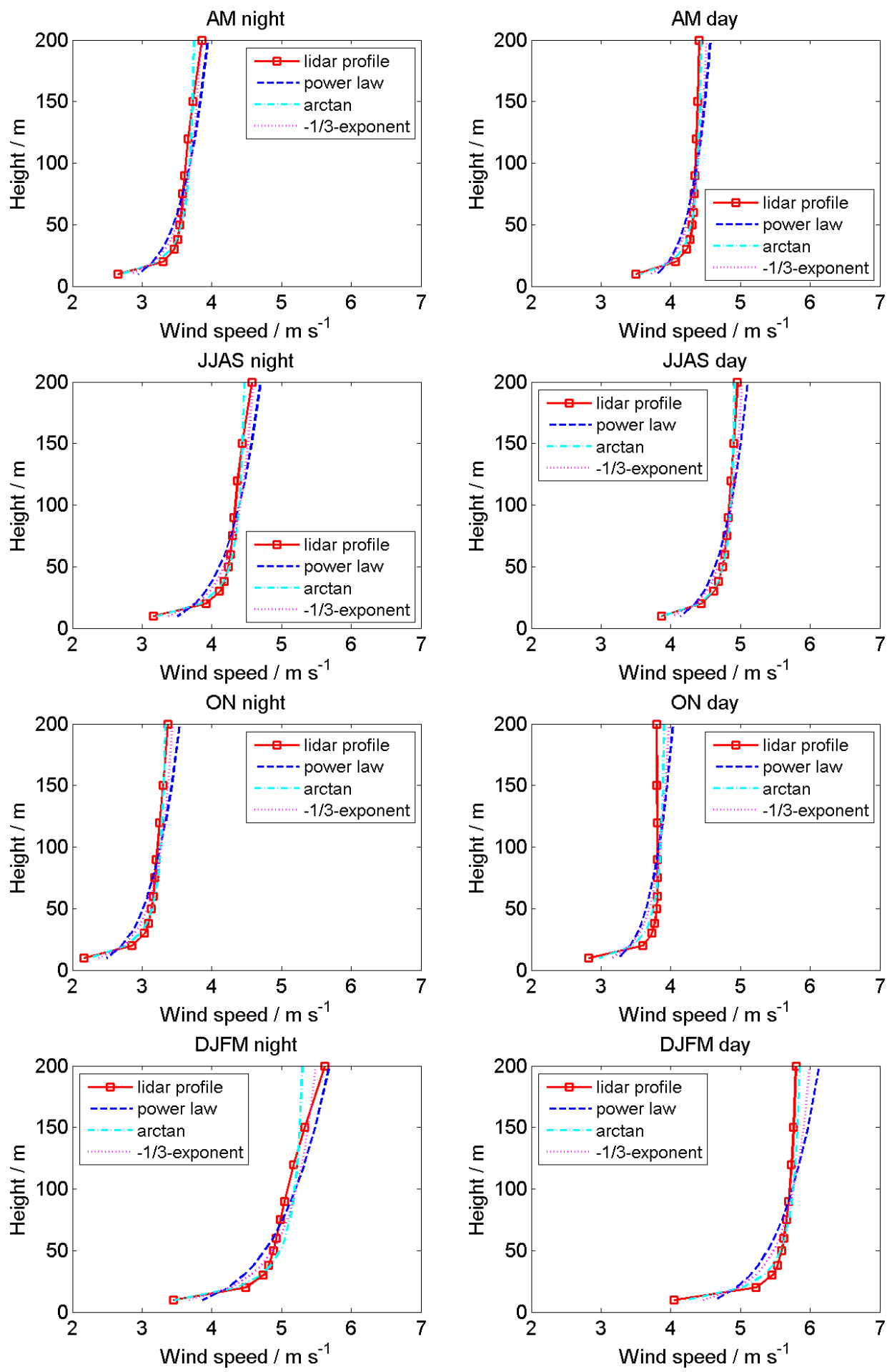

Figure 4: Plots of the observed wind profiles and the three fitted profile models (power law, -1/3-exponent, and arctan) for the four seasons (AM, JJAS, ON, and DJFM) and the two diurnal time periods (night and day). The solid lines with square markers are the measured profile curves with the markers at the observation heights. The dashed lines are the three fitted model curves. 


\section{$\underline{4.1 \text { Results for power-law profile }}$}

Fig. 5 is a plot of the values of $\alpha$ obtained from the curve fitting. These values are also tabulated in Table 1 . From the figure and table, $\alpha$ can be seen to vary seasonally with the smallest value obtained in AM. It then increases through the seasons of JJAS and $\mathrm{ON}$, and the largest value is obtained in DJFM. The seasonal variation is the same for both the night and day profiles. In addition, $\alpha$ shows a clear diurnal variation with the values obtained from the night profiles being consistently larger than that obtained from the corresponding day profiles. Interestingly, the only value of $\alpha$ that is close to the commonly-cited value of $1 / 7$ is that from the DJFM night profile. This is also the largest value of $\alpha$ obtained in this study. While $\alpha$ alone cannot be considered as a reliable indicator of the atmospheric stability, the DJFM night profile does correspond to a mean atmospheric condition with the lowest temperature among all of the profiles. This might suggest that the observed tropical atmosphere is inherently unstably stratified and that a neutral stability assumption cannot realistically apply.

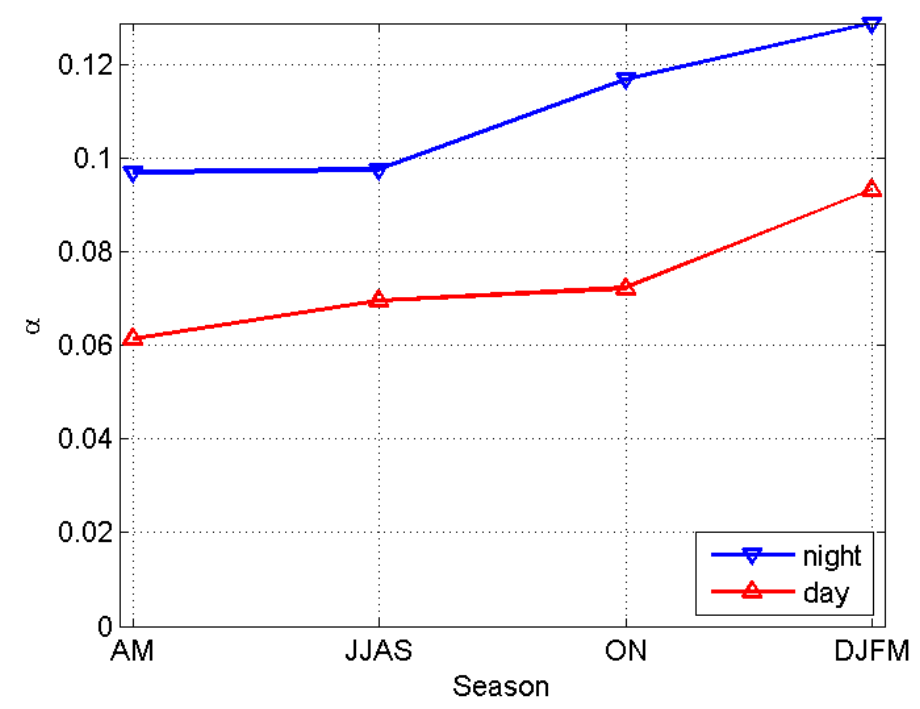

Figure 5: Plot of the fitted values of $\alpha$. The upper line is obtained from the night profiles whereas the lower line is from the day profiles.

\begin{tabular}{|c|c|c|}
\hline & \multicolumn{2}{|c|}{$\boldsymbol{\alpha}$} \\
\hline & night & day \\
\hline AM & 0.097 & 0.061 \\
\hline JJAS & 0.098 & 0.070 \\
\hline ON & 0.117 & 0.072 \\
\hline DJFM & 0.129 & 0.093 \\
\hline
\end{tabular}

Table 1: Tabulated values for $\alpha$.

From Fig. 4, it can be concluded that the fitted power-law curves are unable to fully capture the shape of the measured wind profiles that all exhibit a 'knee' at the height of about $20 \mathrm{~m}$ to $40 \mathrm{~m}$ where the wind gradient (rate of increase of the wind speed with respect to height) decreases sharply. Above the knee, the wind speed plateaus rapidly and reaches a near constant at the height of about $60 \mathrm{~m}$. This behaviour of the measured profiles is in contrast to that displayed by the power-law curves where, in line with the shape of the power-law function, the decrease in the wind gradient is smooth and gradual. The result is an under-prediction of wind speeds by the fitted power-law profiles at the lower heights and an over-prediction at the upper heights. While the 
observed errors in wind speed appear to be small, this, together with the generally low wind speeds, can result in fairly large errors for some applications such as in the prediction of wind power output where the power scales with the cube of wind speed. For example at the $200 \mathrm{~m}$ height, the error in power prediction for DJFM day (observed: $5.79 \mathrm{~m} \mathrm{~s}^{-1}$ vs. power law: $\left.6.13 \mathrm{~m} \mathrm{~s}^{-1}\right)$ would be about $19 \%$. Even the relatively small error in wind speed for JJAS day (observed: $4.96 \mathrm{~m} \mathrm{~s}^{-1}$ vs. power law: $5.10 \mathrm{~m} \mathrm{~s}^{-1}$ ) would result in an error of about $9 \%$. Another observation specific to the measured night profiles is the existence of an inflection point at about $100 \mathrm{~m}$, above which the wind gradient starts to increase. The reason for this is unclear but one can assume that it is related to the more stably stratified (or less unstably stratified) atmosphere associated with the night-time conditions. While this feature allows the power-law profiles to more closely fit the observed wind profiles, it does not change that the fundamental shape of the profile was not captured.

\section{$\underline{4.2 \text { Results for }-1 / 3 \text {-exponent model }}$}

Figs. $6 \mathrm{a}$ and $6 \mathrm{~b}$ and Table 2 show the curve-fitted values of parameters $u_{\beta}$ and $\beta$ for the -1/3-exponent profile model. From Fig. $6 \mathrm{a}$, it can be observed that $u_{\beta}$ has the largest value in DJFM, followed by JJAS, and then followed by the inter-monsoon seasons $\mathrm{AM}$ and $\mathrm{ON}$. Noting that $u_{\beta}$ is the wind speed a fitted profile converges to and thus is a proxy of the observed wind speeds, this implies that the observed wind speeds were the highest during DJFM, followed by JJAS, and then by the inter-monsoon seasons. This is consistent with the known seasonal variation of the wind speed as described earlier. Diurnally, the observed values of $u_{\beta}$ are larger for the day profiles as compared to the night profiles. This implies that the wind speeds are higher during the day than during the night. This is in agreement with the diurnal variation of the wind speed observed in the power-law results.

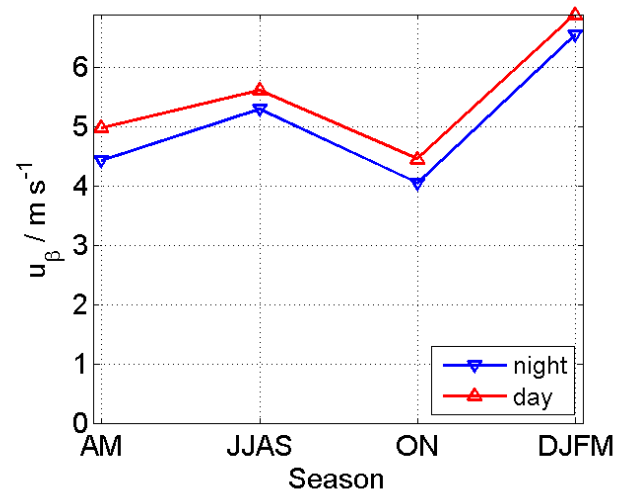

(a)

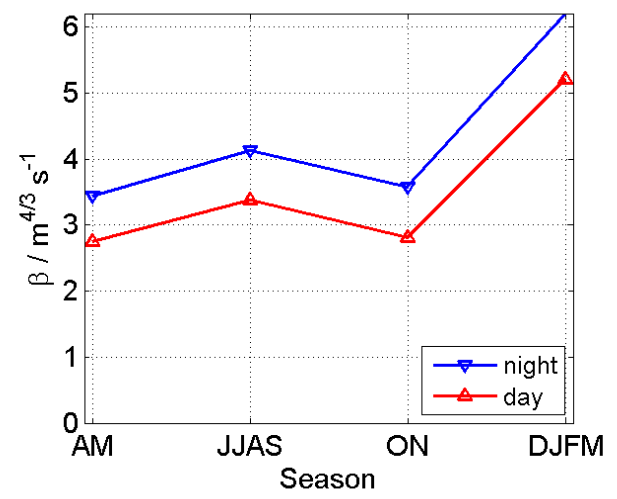

(b)

Figure 6: Plots of the fitted values of parameters (a) $u_{\beta}$ and (b) $\beta$.

\begin{tabular}{|c|c|c|c|c|}
\hline & \multicolumn{2}{|c|}{$\boldsymbol{u}_{\boldsymbol{\beta}}$} & \multicolumn{2}{c|}{$\boldsymbol{\beta}$} \\
\hline & night & day & night & day \\
\hline AM & 4.43 & 4.98 & 3.43 & 2.74 \\
\hline JJAS & 5.29 & 5.60 & 4.12 & 3.39 \\
\hline ON & 4.04 & 4.45 & 3.58 & 2.80 \\
\hline DJFM & 6.55 & 6.88 & 6.19 & 5.21 \\
\hline
\end{tabular}

Table 2: Tabulated values for the parameters $u_{\beta}$ and $\beta$. 
The parameter $\beta$ is observed in Fig. $6 \mathrm{~b}$ to have the largest value in DJFM, followed by JJAS. The smallest values are obtained in the inter-monsoon seasons and both seasons yield similar values. Recall that $\beta$ controls the sharpness of the knee and thus determines how quickly a fitted profile converges towards $u_{\beta}$, with a smaller $\beta$ indicating faster convergence with height. This implies that the fitted profiles converge most rapidly during the inter-monsoon seasons, followed by JJAS, and then by DJFM, which is the slowest. It is interesting to note that the seasonal variation of $\beta$ is the same as $u_{\beta}$ but is not at all correlated to that of $\alpha$ or $\tau$ ( $\tau$ is described in the next section.). This might be explained as an artifact of the fact that the -1/3-exponent model is different from the power-law and arctan models in that the wind speed in the -1/3-exponent profile does not go to zero at height $z=0$. Diurnally, $\beta$ is observed to be larger for the night profiles as compared to the day profiles. This implies that the fitted profiles converge faster during the day than during the night. Since the inflection point in the measured night profiles has the effect of extending the knee of a fitted profile and thus making it more blunt, this diurnal result is expected.

\section{$\underline{4.3 \text { Results for arctan model }}$}

Fig. 7a and Fig. 7b and Table 3 show the curve-fitted values of parameters $u_{\tau}$ and $\tau$ for the arctan profile model. From Fig. 7a, it can be observed that $u_{\tau}$ has the largest value in DJFM, followed by JJAS, and then followed by the inter-monsoon seasons AM and ON. Noting that $u_{\tau}$ is the wind speed a fitted arctan profile converges to and thus is an indicator of the observed wind speeds, this implies that the observed wind speeds are the highest during DJFM, followed by JJAS, and then by the inter-monsoon seasons. This is again consistent with the known seasonal variation of the wind speed as described earlier. Diurnally, the observed values of $u_{\tau}$ are, similar to $u_{\beta}$, larger for the day profiles as compared to the night profiles. This implies that the wind speeds are higher during the day than during the night. This is in agreement with the diurnal variation of the wind speed observed in the power-law results and it also matches the 1/3-exponent model results.

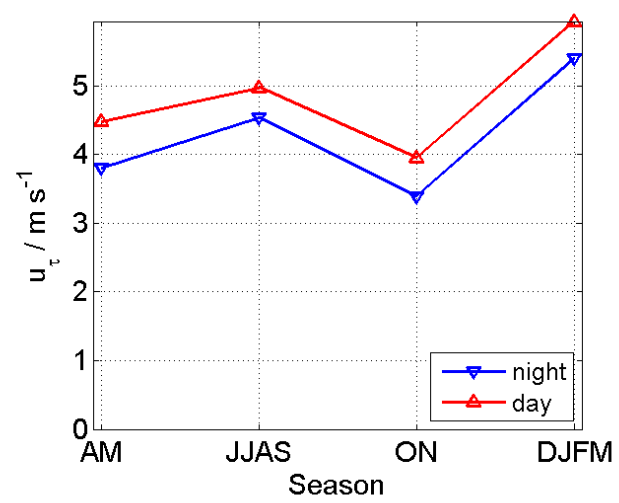

(a)

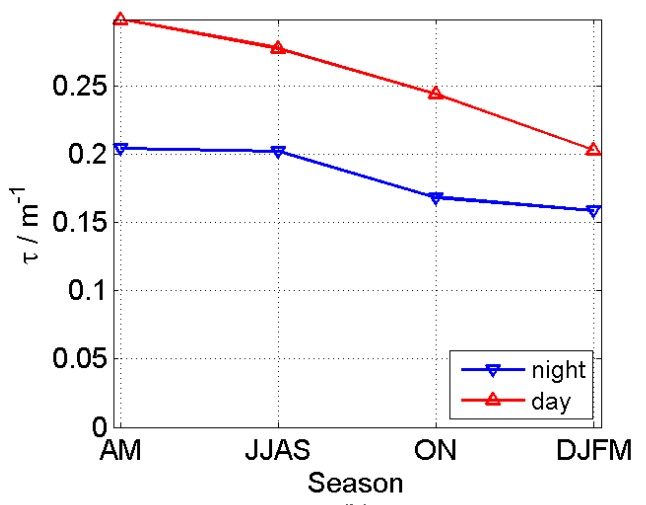

(b)

Figure 7: Plots of the fitted values of parameters (a) $u_{\tau}$ and (b) $\tau$. 


\begin{tabular}{|c|c|c|c|c|}
\hline & \multicolumn{2}{|c|}{$\boldsymbol{u}_{\boldsymbol{\tau}}$} & \multicolumn{2}{c|}{$\boldsymbol{\tau}$} \\
\hline & night & day & night & day \\
\hline AM & 3.80 & 4.48 & 0.205 & 0.299 \\
\hline JJAS & 4.53 & 4.97 & 0.202 & 0.278 \\
\hline ON & 3.39 & 3.95 & 0.169 & 0.244 \\
\hline DJFM & 5.40 & 5.94 & 0.159 & 0.204 \\
\hline
\end{tabular}

Table 3: Tabulated values for the parameters $u_{\tau}$ and $\tau$.

The parameter $\tau$ is observed in Fig. 7b to have the largest value in AM. $\tau$ then decreases through the seasons JJAS and ON, and the smallest value is obtained in DJFM. Recall that $\tau$, analogous to $\beta$, controls the sharpness of the knee and thus determines how quickly a fitted arctan profile converges towards $u_{\tau}$, with a larger $\tau$ indicating faster convergence with height. This implies that the fitted profiles converge most rapidly during AM and most slowly during DJFM. The seasonal variation is, aside from both having the slowest convergence during DJFM, not the same as the one inferred from $\beta$. Diurnally, $\tau$ is observed to be larger for the day profiles as compared to the night profiles. This implies that the fitted arctan profiles converge faster during the day than during the night. The diurnal variation is in agreement with that inferred from $\beta$ and could be attributed to the same effect of the inflection point.

Another interesting observation is the apparent inverse correlation that exists between $\tau$ and $\alpha$ which is evident when comparing Figs. 5 and 7b. From Fig. 5, $\alpha$ is larger for the night profiles when compared to the day profiles but in Fig. 7b, $\tau$ is smaller for the night profiles. Furthermore, the value of $\alpha$ increases through the seasons from AM to DJFM but in the case of $\tau$, it decreases. The reason for this relationship can be attributed to how the fitted profile curves attempt to capture the shape of the measured wind profiles. For the case of a power-law fit, a smaller $\alpha$ is indicative of a sharper decrease of the wind gradient with height whereas for the case of an arctan model fit, this would translate into a sharper knee and result in a larger value of $\tau$.

\subsection{Results and comparison of the SSEs}

Fig. 8 shows the comparison plot of the SSEs for the three profile models: power-law, -1/3-exponent, and arctan. The errors appear to be the largest during the DJFM season as can be seen clearly in the figure. One may also note that the errors vary seasonally and diurnally in a similar manner for all the three profile models, except for the arctan model during DJFM. For all profile models, the night and day errors are similar during AM, while during JJAS the error is larger during the night. During ON, however, the trend reverses and the day error becomes larger. During DJFM, the day error remains larger than the night error for the power-law and -1/3-exponent profile models, while the night error becomes the larger one for the arctan model. This is interesting as the measured DJFM night wind profile has the most pronounced inflection point among all the profiles and is perhaps the closest match to the profile of a traditional power-law curve. It explains why the power-law curve for DJFM night achieves a smaller error compared to the corresponding day curve while the arctan model, which have a much sharper drop in the wind gradient with height, demonstrates the opposite. Overall, as evident in Fig. 4, the -1/3-exponent and arctan models (for the day profiles at least) still suffer the same issue of overprediction at higher heights and underprediction at lower heights as the power-law profile model. However, they are able to achieve smaller 
fitting errors because the shapes of their profile curves are able to more closely match that of the measured wind profiles.

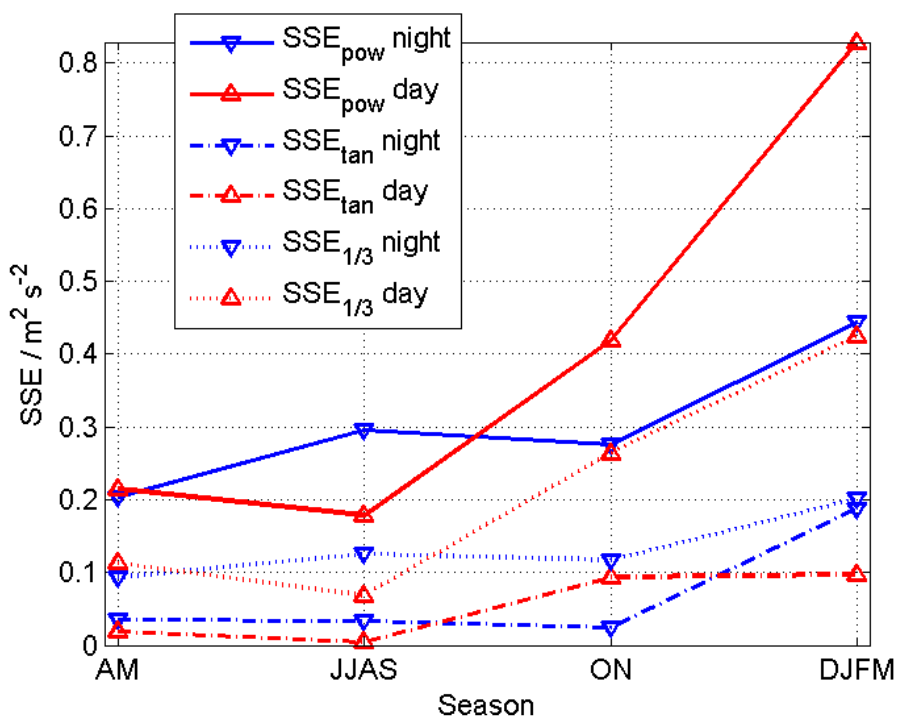

Figure 8: Comparison of the sum-of-squared errors (SSEs) of the three profile models.

Comparing the errors of the three profile models, it is clear that the arctan model is the best performing model, followed by the -1/3-exponent model, and then lastly the power law. All the errors observed for the power-law model are larger than the corresponding errors for the -1/3-exponent model and these were in turn larger than those for the arctan model. Even the -1/3-exponent profile model, which is based on the free convection theory, is unable to outperform the arctan profile model, which is inspired solely by the shape of the observed wind profiles. It thus appears that the real wind profiles observed in this study have wind gradients that decrease so rapidly with height that the arctan profile model results in better predictions.

\section{$\underline{4.5 \text { Directional properties of } u_{\tau} \text { and } \tau}$}

After concluding that the arctan model is superior in the previous section, we now investigate the profile parameters further. Fig. 9 shows the values of $u_{\tau}$ obtained when considering winds coming from only one of four directional quadrants, as defined by the wind direction measured by lidar at the $38 \mathrm{~m}$ height. The quadrants are: northeast $(\mathrm{NE})$, southeast (SE), southwest (SW), and northwest (NW). It can be seen for the DJFM season in Fig. 9d that the largest $u_{\tau}$ is recorded in the NE quadrant whereas the smallest is in the SW quadrant. Noting again that $u_{\tau}$ is a proxy of the average wind speed, it can be deduced that the strongest winds during DJFM come from the northeastern quadrant. This is expected as that is the direction of the prevailing northeast monsoon winds during DJFM. For JJAS, in Fig. 9b, the strongest winds can be seen to come from the SE quadrant, followed by SW, and with the weakest winds from the NE quadrant. While there appears to be a contradiction with the prevailing wind direction during the southwest monsoon, it is known that the southwest monsoon winds in Singapore during JJAS tend to be more southerly rather than southwesterly [35]. Thus, the results simply show that the southerly winds with easterly components tend to be stronger compared to those with westerly components. 
The results obtained for the inter-monsoon seasons are less obvious, as one would expect given the variable wind direction during the two inter-monsoon seasons. For AM (Fig. 9a), the strongest winds come from the SE and NE quadrants, which apparently show the transition from the NE-dominant winds during DJFM to the SEdominant winds during JJAS. For ON (Fig. 9c) however, such transition characteristics are absent. The strongest winds come from the NW quadrant during the day hours but come instead from the SE quadrant during the night hours. Compared to the seasonal influence, the diurnal influence on the directional variations of $u_{\tau}$ is also not apparent. In almost all cases, with the exception of NW quadrant during AM, SE quadrant during $\mathrm{ON}$, and SW quadrant during DJFM, the day values of $u_{\tau}$ are larger than the corresponding night values. This is the same trend observed in the non-directional analysis reported in the Section 4.3. While the exception cases may be seen as the direction-specific diurnal influences, the fact that they occur in different quadrants during different seasons mean that no meaningful conclusions can be drawn. It is observed that the directional variation of $u_{\tau}$ is seasonally influenced, most notably for JJAS and DJFM where the quadrant with the largest value of $u_{\tau}$ coincide with the direction of the prevailing wind. While this by itself does not preclude the existence of non-seasonal direction-only influences, the lack of a consistence pattern of variation across the different seasons implies that such effects are overshadowed by the seasonal influence. As such, it can be concluded that the seasonal influence on the directional variations of $u_{\tau}$ is dominant.

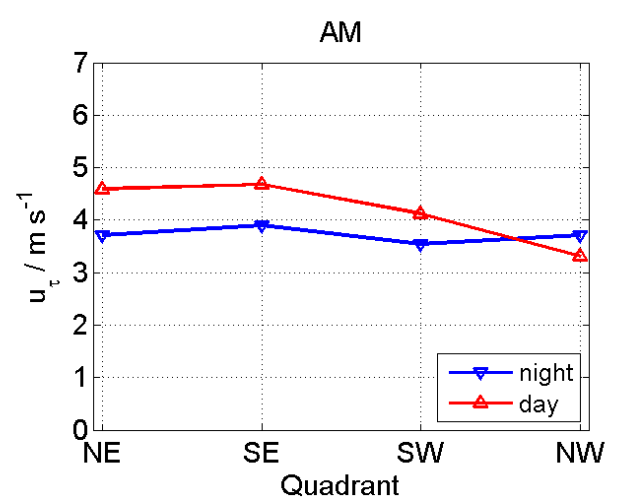

(a)

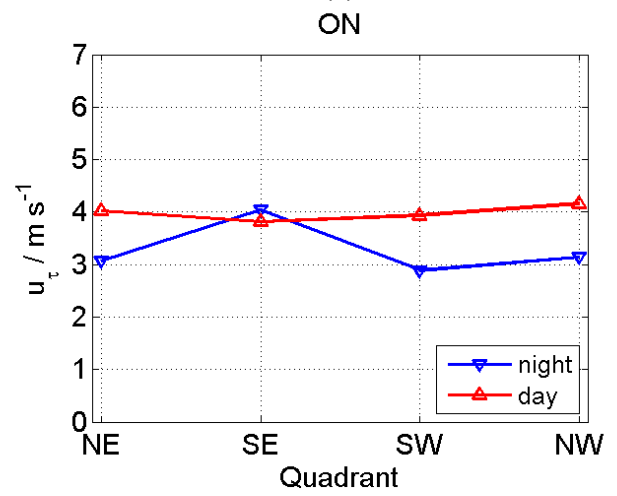

(c)

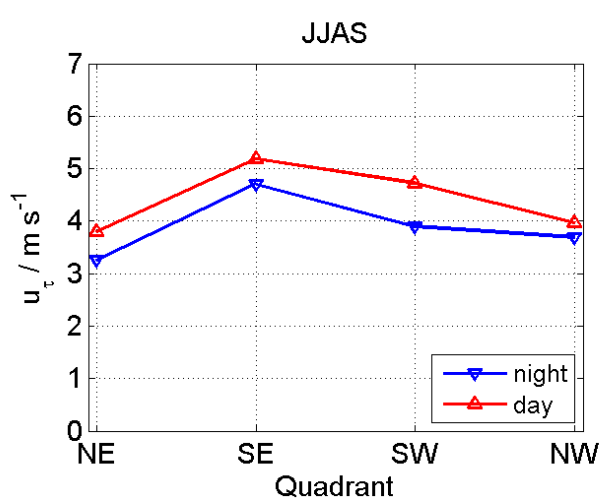

(b)

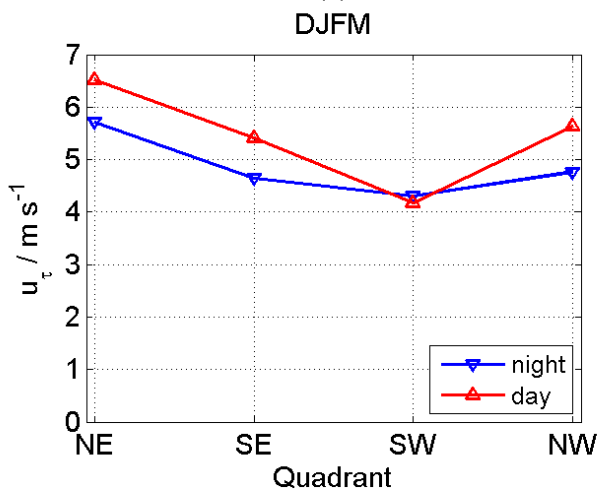

(d)

Figure 9: The parameter $u_{\tau}$ in the four directional quadrants for seasons (a) AM, (b) JJAS, (c) ON, and (d) DJFM. The four quadrants are: northeast $\left(\mathrm{NE} 0^{\circ}-90^{\circ}\right)$, southeast $\left(\mathrm{SE} 90^{\circ}-180^{\circ}\right)$, southwest $\left(\mathrm{SW} 180^{\circ}-270^{\circ}\right)$, and northwest $\left(\mathrm{NW} 270^{\circ}-360^{\circ}\right)$. 


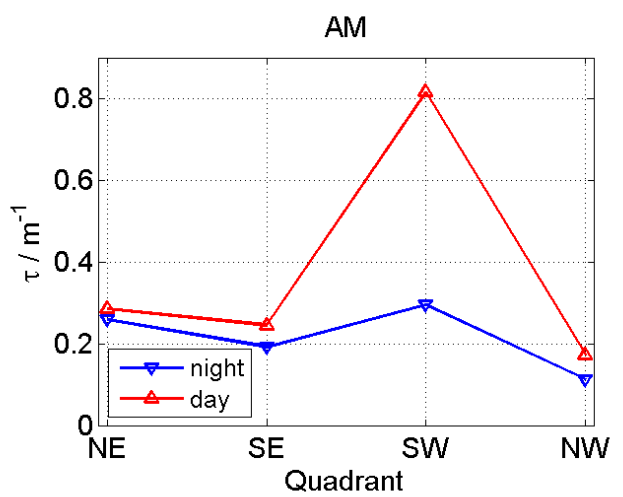

(a)

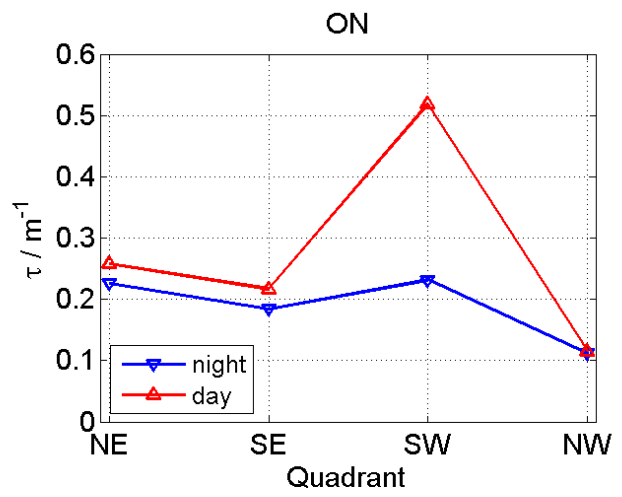

(c)

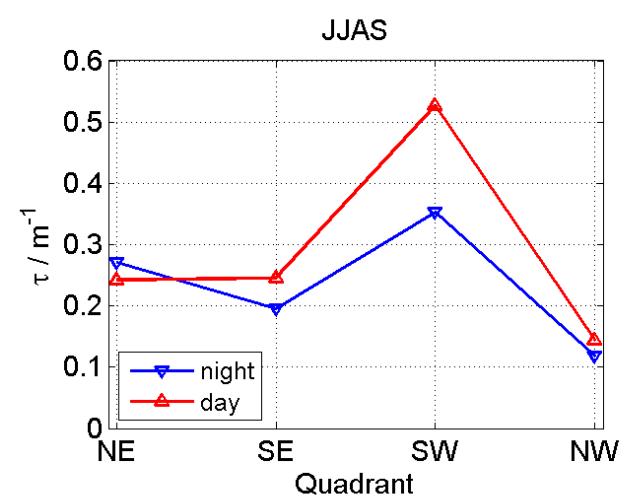

(b)

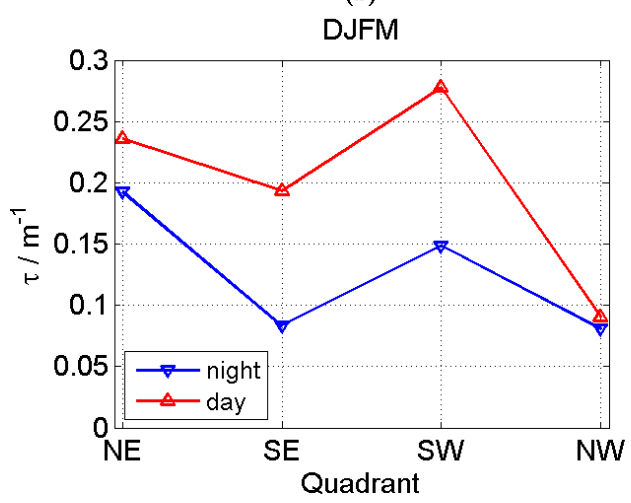

(d)

Figure 10: The parameter $\tau$ in the four directional quadrants for seasons (a) AM, (b) JJAS, (c) ON, and (d) DJFM. The four quadrants are: northeast (NE $\left.0^{\circ}-90^{\circ}\right)$, southeast $\left(\mathrm{SE} 90^{\circ}-180^{\circ}\right)$, southwest $\left(\mathrm{SW} 180^{\circ}-270^{\circ}\right)$, and northwest $\left(\mathrm{NW} 270^{\circ}-360^{\circ}\right)$.

From Fig. 10, which shows the directional results for $\tau$, it can be observed that (with the exception of DJFM night) all the seasons follow the same trend: the largest $\tau$ in the SW quadrant, followed by the easterly quadrants, and then lastly the smallest $\tau$ in the NW quadrant. Recall that a larger $\tau$ indicates a sharper knee. This implies that the profile of winds coming from the southwestern quadrant has the sharpest knee whereas that coming from the northwestern quadrant has the bluntest. The consistency of the results across the different seasons and night/day gives confidence to the observation and it can be inferred that $\tau$ is influenced by properties of the atmospheric flow that vary with direction but remain constant throughout the year in each direction. A strong possibility for such a property is the surface roughness. The reason as to why the DJFM night result does not follow the trend may be attributed to the very-pronounced inflection point noted in the DJFM night profile distorting the curve-fit results. In all, it was shown here that the variation of average wind speed with direction is predominantly influenced by seasonal changes whereas that of the sharpness of the profile knee is controlled by the directional properties, possibly the surface roughness. 

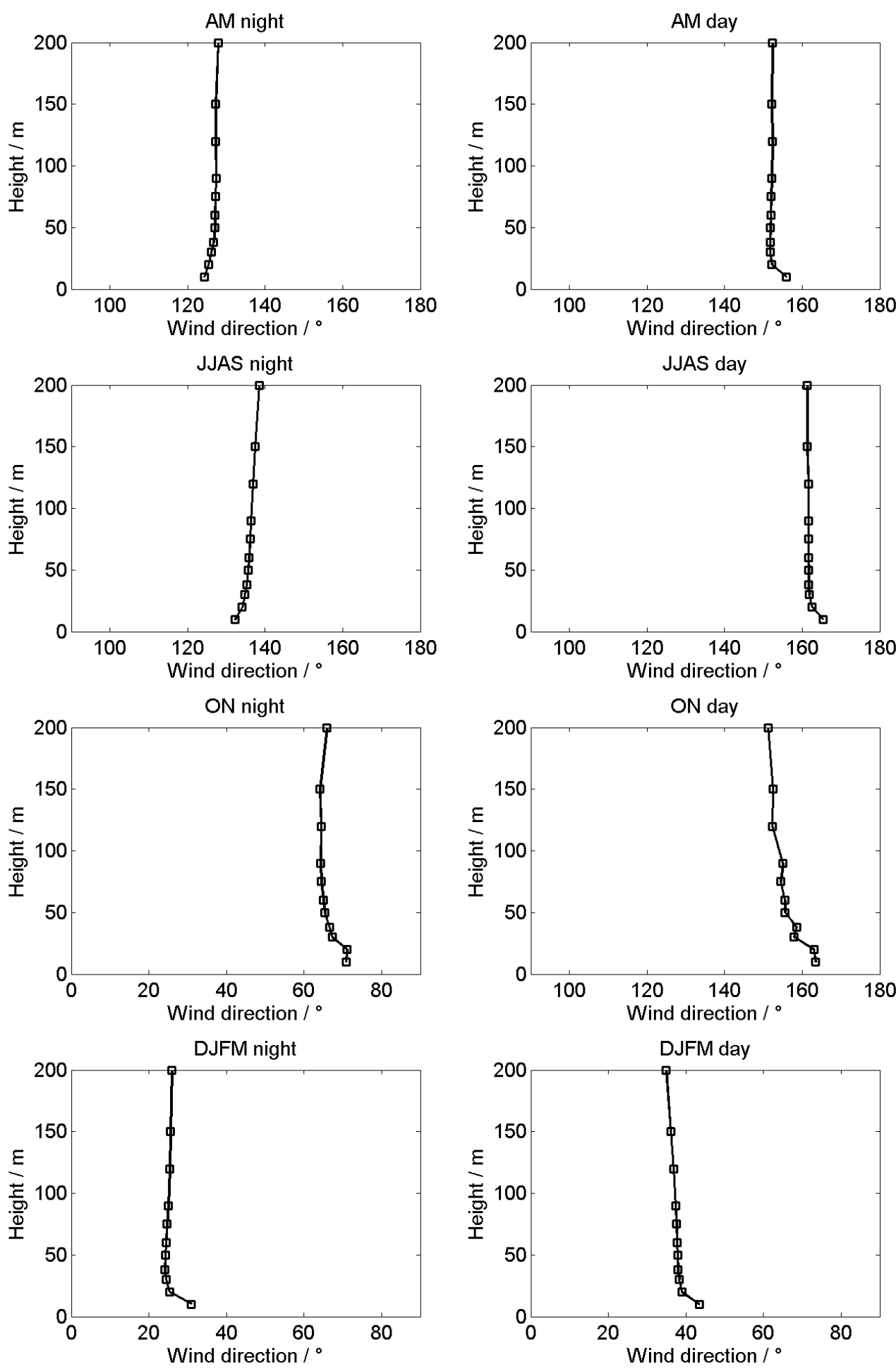

Figure 11: Plots of the observed variation in the prevailing wind direction with height for the four seasons (AM, JJAS, ON, and DJFM) and the two diurnal time periods (night and day). Directions are measured in degrees clockwise from the cardinal north. The square markers denote the observation heights. 


\subsection{Wind direction profiles}

Fig. 11 shows the observed variation in the prevailing wind direction with height (i.e. the wind direction profile) for the four seasons and the two diurnal time periods. The wind directions are obtained by taking the vector mean of the wind velocity at each height and then using the direction of the resultant mean vector. Following meteorological conventions, the wind directions reported here are the direction where the wind is coming from, measured clockwise from the cardinal north.

The observed wind direction profiles can be characterised by the direction of the prevailing wind as well as by the sense of the wind veering with height. Considering first the main monsoon seasons of JJAS and DJFM, it can be seen that the prevailing wind is predominantly southwesterly during JJAS and northeasterly during DJFM. This is in line with the known seasonal trend in the wind direction represented in Fig. 2. Furthermore, in most cases the wind veers overall towards the left with increasing height with the exception of the JJAS night profile, which veers towards the right. The DJFM night profile also exhibits a peculiar characteristic where the wind initially veers towards the left, but the veering then reverses with further increase in height. For the inter-monsoon seasons, both day profiles exhibit similar characteristics to each other and they are also similar to the JJAS day profile in terms of the prevailing wind direction and the sense of the veering. The night profiles, however, are different from each other with the AM night profile being more similar to JJAS night whereas the ON night profile is more similar to DJFM night. Overall, the range of the veering observed within the lowest $200 \mathrm{~m}$ boundary layer ranges from between $4^{\circ}$ to $12^{\circ}$ with the most pronounced veering occurring within the lowest $40 \mathrm{~m}$.

\section{$\underline{4.7 \text { Practical implications }}$}

The results obtained for the observed wind profiles have practical implications for the application of wind energy in the deep tropics. It was noted that the measured profiles exhibit a knee where the wind gradient drops sharply across it and that the wind speed above the knee rapidly plateaus. The wind speed increments above the $60 \mathrm{~m}$ height are small in most cases. While the night profiles also display an inflection point at above $100 \mathrm{~m}$ where the wind gradient increases again, wind speeds in the night profiles are lower compared to the day profile of the same season. Thus, unlike in the extra-tropics where wind turbine towers are built to immense heights to capture the higher wind speeds, towers of heights above $60 \mathrm{~m}$ might be unnecessary in the tropics and would not result in significantly higher power generation. Also, the measured wind speeds were low, as expected, with the highest mean wind speed at $90 \mathrm{~m}$ being only $5.7 \mathrm{~m} \mathrm{~s}^{-1}$, obtained for the DJFM day profile. This means that wind turbines designed specifically for low wind speed applications will be desirable or even necessary. 


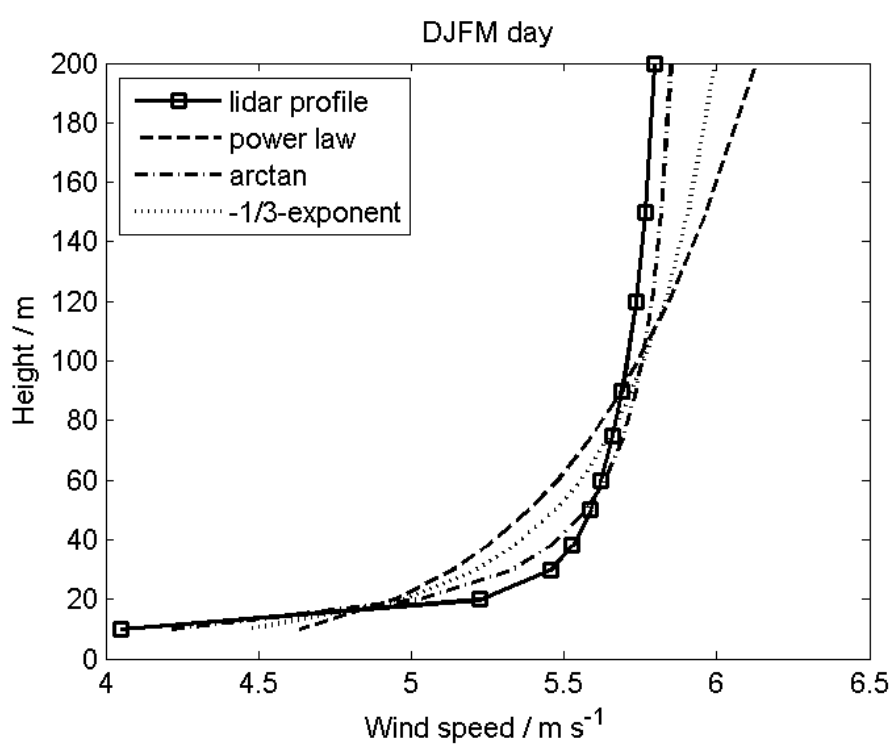

Figure 12: Plot of the lidar wind profile and the three predicted model profiles (power law, -1/3-exponent, and arctan) for DJFM day. The plot is the same as the 'DJFM day' panel in Fig. 4 but with a rescaled wind speed axis.

Furthermore, it was demonstrated that the arctan model is the superior model in predicting the tropical vertical wind profile. Fig. 12 shows the observed lidar profile plotted together with the three model profiles for DJFM day and serves to illustrate this point. Unlike the power law, which is a scaling model with a single parameter, the arctan profile model has two parameters that completely determine the profile without any extrapolation. This gives some insights into the nature of the observed wind profiles. Firstly, the wind speed that the profile converges to above the knee (and parameterised by $u_{\tau}$ ) is independent of the wind speeds measured at any of the lower heights. This means that the value of this definitive wind speed must be determined separately through measurements at a significant height above the ground. The traditional method of extrapolating wind speed from a lower height no longer apply and the wind speed measured near the surface, such as at $10 \mathrm{~m}$, cannot be used for predicting wind speeds at typical wind turbine hub heights. Secondly, two wind speed measurements are required to fully determine the profile. This second measurement must be made within the knee of the profile and can be used to determine the parameter (in this case, $\tau$ ) which controls its sharpness.

In practice however, it is still possible to construct an arctan model profile, through mathematical manipulation, from wind speed measurements at two separate heights near the surface. In such an approach, the sharpness of the knee can first be inferred from the two measurement points and the value of $\tau$ is calculated by iteration. The parameter $u_{\tau}$ can then be determined using either of the measurement points given the known value of $\tau$. This approach is not ideal as it can be seen in Fig. 12 that the discrepancy between the model profile and the observed profile is the largest at heights near the surface within the knee and would thus make a relatively poor basis for the construction of a model profile. Nevertheless, the arctan model still outperforms the power-law model at these heights and the constructed arctan model profile would likely give more accurate wind speed predictions over traditional power-law extrapolation. 


\section{Conclusion}

From this study, it was found that the fitted power-law profiles were unable to capture the shape of the measured wind profiles due to a sharp drop in the wind gradient across a knee in the observed profiles and the subsequent plateauing of the wind speed above the knee. The power-law curves were unable to capture the sharp decrease in the wind gradient and the shape of the curves also did not accommodate the feature of a plateauing wind speed. With regards to the wind shear coefficient $\alpha$, the values obtained in this study were always lower than the commonly-cited value of $1 / 7$. In light of these observations, it was suggested that there is likely little value in having wind turbines in the tropics above the height of $60 \mathrm{~m}$. It was also suggested that the power-law model should not be used as a basis for wind speed prediction in the tropics.

Next, two alternative profile models were introduced that were able to better fit the observed wind profiles. They are the $-1 / 3$-exponent model and the $\arctan$ model. A systematic investigation of the seasonal and diurnal characteristics of their parameters was reported. By comparison of the sum-of-squared errors, it was determined that the arctan profile model was able to produce the best predictions. This is likely due to its ability to better capture the sharp decrease in the wind gradient across the knee. The results also imply that the wind speed above the knee must be measured separately and cannot be extrapolated from a lower height, although a procedure was described where two near-surface measurements can be used as a proxy.

While the work reported here is certainly not the definitive word on the matter, it was shown that there are significant discrepancies between the behaviour of the tropical and extra-tropical atmospheres within the boundary layer. Thus, more research into the tropical atmospheric boundary layer is needed to achieve a more comprehensive understanding of its characteristics and attain greater confidence in the prediction of wind speeds for practical applications. The introduction of the arctan model in the present work will enhance the confidence in using a simple estimation procedure for tropical regions, similar to the power-law for the mid-latitude regions.

The authors declare no conflict of interest.

The present research was supported by the EDB Energy Innovation Research (EIRP) grant S14-1187-NRFEIPO-EIRP-IHL.

\section{References}

1. Saidur R, Islam MR, Rahim NA, Solangi KH. A review on global wind energy policy. Renewable and Sustainable Energy Reviews. 2010;14:1744-1762. doi:10.1016/j.rser.2010.03.007.

2. Kaldellis JK, Zafirakis D. The wind energy (r)evolution: A short review of a long history. Renewable Energy. 2011;36:1887-1901. doi:10.1016/j.renene.2011.01.002. 
3. Tummala A, Velamati RK, Sinha DK, Indraja V, Krishna VH. A review on small scale wind turbines. Renewable and Sustainable Energy Reviews. 2016;56:1351-1371. doi:10.1016/j.rser.2015.12.027.

4. Kishore RA, Marin A, Priya S. Efficient Direct-Drive Small-Scale Low-Speed Wind Turbine. Energy Harvesting and Systems. 2014;1(1-2):27-43. doi:10.1515/ehs-20140004.

5. Petersen EL, Troen I. Wind conditions and resource assessment. WIREs Energy and Environment. 2012;1:206-217. doi:10.1002/wene.4

6. Lin J-S, Hildemann LM. Analytical solutions of the atmospheric diffusion equation with multiple sources and height-dependent wind speed and eddy diffusivities. Atmospheric Environment. 1996;30(2):239-254. doi:10.1016/1352-2310(95)00287-9.

7. Högström U. Non-Dimensional Wind and Temperature Profiles in the Atmospheric Surface Layer: A Re-evaluation. Boundary-Layer Meteorology. 1988;42:55-78. doi:10.1007/BF00119875.

8. Gryning SE, Batchvarova E, Brümmer B, Jørgensen H, Larsen S. On the extension of the wind profile over homogeneous terrain beyond the surface boundary layer. Boundary-Layer Meteorology. 2007;124:251-268. doi:10.1007/s10546-007-9166-9.

9. Sathe A, Gryning SE, Peña A. Comparison of the atmospheric stability and wind profiles at two wind farm sites over a long marine fetch in the North Sea. Wind Energy. 2011;14:767-780. doi:10.1002/we.456.

10. Peña A, Floors R, Gryning SE. The Høvsøre Tall Wind-Profile Experiment: A Description of Wind Profile Observations in the Atmospheric Boundary Layer. Boundary-Layer Meteorology. 2014;150:69-89. doi:10.1007/s10546-013-9856-4.

11. Holton JR. Tropical Dynamics. In: An Introduction to Dynamic Meteorology. 4th ed. Burlington, MA: Elsevier Academic Press; 2004:370-406.

12. Emeis S. Power Law. In: Wind Energy Meteorology. Berlin Heidelberg: SpringerVerlag; 2013:33-33.

13. Sisterson DL, Hicks BB, Coulter RL, Wesely ML. Difficulties in Using Power Laws for Wind Energy Assessment. Solar Energy. 1983;31(2):201-204. doi:10.1016/0038092X(83)90082-8.

14. Foken T. 50 Years of the Monin-Obukhov Similarity Theory. Boundary-Layer Meteorology. 2006;119:431-447. doi:10.1007/s10546-006-9048-6.

15. Grachev AA, Fairall CW, Bradley EF. Convective Profile Constants Revisited. Boundary-Layer Meteorology. 2000;94:495-515. doi:10.1023/A:1002452529672.

16. Akylas E, Tombrou M. Interpolation Between Businger-Dyer Formulae and Free Convection Forms: A Revised Approach. Boundary-Layer Meteorology. 2005;115:381-398. doi:10.1007/s10546-004-1426-3. 
17. Srivastava P, Sharan M. An Analytical Formulation of the Monin-Obukhov Stability Parameter in the Atmospheric Surface Layer Under Unstable Conditions. Boundary-Layer Meteorology. 2017;165:371-384. doi:10.1007/s10546-017-0273-y.

18. Kettle AJ. Unexpected vertical wind speed profiles in the boundary layer over the southern North Sea. Journal of Wind Engineering and Industrial Aerodynamics. 2014;134:149-162. doi:10.1016/j.jweia.2014.07.012.

19. Albani A, Ibrahim MZ. Wind Energy Potential and Power Law Indexes Assessment for Selected Near-Coastal Sites in Malaysia. Energies. 2017;10(3):307. doi:10.3390/en10030307.

20. Sinha S, Chandel SS. Wind shear analysis for different wind turbine hub heights in a western himalayan terrain. 2016 7th India International Conference on Power Electronics (IICPE). 2016. doi:10.1109/IICPE.2016.8079504.

21. Okorie ME, Inambao F, Chiguvare Z. Evaluation of Wind Shear Coefficients Surface Roughness and Energy Yields over Inland Locations in Namibia. Procedia Manufacturing. 2017;7:630-638. doi:10.1016/j.promfg.2016.12.094.

22. Hsu SA. Determination of the Power-Law Wind Profile Exponent on a Tropical Coast. Journal of Applied Meteorology. 1982;21:1187-1190. doi:10.1175/15200450(1982)021<1187:DOTPLW>2.0.CO;2.

23. Gualtieri G. Atmospheric stability varying wind shear coefficients to improve wind resource extrapolation: A temporal analysis. Renewable Energy. 2016;87:376-390. doi:10.1016/j.renene.2015.10.034.

24. Kikumoto H, Ooka R, Sugawara H, Lim J. Observational study of power-law approximation of wind profiles within an urban boundary layer for various wind conditions. Journal of Wind Engineering and Industrial Aerodynamics. 2017;164:1321. doi:10.1016/j.jweia.2017.02.003.

25. Walter K, Weiss CC, Swift AHP, Chapman J, Kelley ND. Speed and Direction Shear in the Stable Nocturnal Boundary Layer. Journal of Solar Energy Engineering. 2009;131:011013. doi:10.1115/1.3035818.

26. Irwin JS. A theoretical variation of the wind profile power-law exponent as a function of surface roughness and stability. Atmospheric Environment. 1979;13:191194. doi:10.1016/0004-6981(79)90260-9.

27. Newman JF, Klein PM. The Impacts of Atmospheric Stability on the Accuracy of Wind Speed Extrapolation Methods. Resources. 2014;3(1):81-105. doi:10.3390/resources3010081.

28. Holtslag MC, Bierbooms WAAM, van Bussel GJW. Extending the diabatic surface layer wind shear profile for offshore wind energy. Renewable Energy. 2017;101:96110. doi:10.1016/j.renene.2016.08.031. 
29. Cook NJ. The Deaves and Harris ABL model applied to heterogeneous terrain. Journal of Wind Engineering and Industrial Aerodynamics. 1997;66:197-214. doi:10.1016/S0167-6105(97)00034-2.

30. Grachev AA, Fairall CW, Zilitinkevich SS. Surface-Layer Scaling for the Convection-Induced Stress Regime. Boundary-Layer Meteorology. 1997;83:423-439. doi:10.1023/A:1000281625985.

31. Holtslag MC, Bierbooms WAAM, van Bussel GJW. Estimating atmospheric stability from observations and correcting wind shear models accordingly. Journal of Physics: Conference Series. 2014;555:012052. doi:10.1088/1742-6596/555/1/012052.

32. Lang S, McKeogh E. LIDAR and SODAR Measurements of Wind Speed and Direction in Upland Terrain for Wind Energy Purposes. Remote Sensing. 2011;3:18711901. doi:10.3390/rs3091871.

33. Mikkelsen T. Lidar-based Research and Innovation at DTU Wind Energy - a Review. Journal of Physics: Conference Series. 2014;524:012007. doi:10.1088/17426596/524/1/012007.

34. The International Electrotechnical Commission (IEC). Wind turbines - Part 12-1: Power performance measurements of electricity producing wind turbines. IEC 6140012-1:2017.

35. Meteorological Service Singapore. Climate of Singapore.

http://www.weather.gov.sg/climate-climate-of-singapore/. Accessed November 26, 2018. 
2020-08-13

\section{Suitability of power-law extrapolation for wind speed estimation on a tropical island}

Tieo, Jing-Jin

Elsevier

Tieo JJ, Skote M, Srikanth N. (2020) Suitability of power-law extrapolation for wind speed estimation on a tropical island. Journal of Wind Engineering and Industrial Aerodynamics, Volume 205, October 2020, Article number 104317

https://doi.org/10.1016/j.jweia.2020.104317

Downloaded from Cranfield Library Services E-Repository 